\title{
BREVES CONSIDERAÇÕES SOBRE O ESTADO DE DIREITO NA MODERNIDADE LÍQUIDA E AS LEIS DE EMERGÊNCIA.
}

Gean Claudio Araujo

Universidade do Oeste Paulista - UNOESTE. Curso de Direito. E-mail: geanclaudio21@gmail.com.

\section{RESUMO}

A pós modernidade trouxe certa efemeridade à sociedade com mudanças valorativas constantes, inclusive na esfera penal. O presente estudo objetivou analisar como essas mudanças afetam o Direito Penal. O trabalho foi embasado em levantamento bibliográfico, com leituras de leis, doutrinas e artigos eletrônicos. Os dados foram examinados com a aplicação do método hipotético dedutivo. Costatou-se que frente a crimes que causam grande comoção popular, o Estado busca criar leis emergenciais como resposta à transpassar sensação de se estar coibindo a criminalidade e garantindo-se a segurança de todos, v.g., projeto de lei 5452/2016 (Brasil, 2016), versando sobre crime de estupro. O resultado da analise de proposta legislativa elaboradas nessas situações foi a constatação de sua ilegitimidade, ilegalidade e ineficácia. São medidas ilusórias. Concluiu-se que se utiliza o Direito Penal (a ultima "ratio") como um simples instrumento de resposta política à sociedade, desvirtuando-o da sua real função, num Estado de Direito.

Palavras-chave: modernidade líquida, direito penal, leis de emergência, fatos de grande comoção.

\section{BRIEF CONSIDERATIONS ON THE RULE OF LAW IN NET MODERNITY AND EMERGENCY LAWS}

\begin{abstract}
Postmodernity brought a certain ephemerality to many aspects of society with constant changes, including in the criminal sphere. The purpose of the present study is to analyze these changes, through research on the legislative process in periods of trouble for society, the methodology found that faced with events of great popular commotion, the legislative response consists in the creation of emergency laws, the illusory sense of being curbed by crime and ensuring security. It is imperative to analyze the real efficiency of legislative proposals that arise in this context; the results demonstrate the ineffectiveness of such projects. We used the present study to study the use of criminal law as an instrument of political response to society.
\end{abstract}

Keywords: Liquid modernity. Criminal Law 


\section{INTRODUÇÃO}

"Como organismo vivo, o Direito está em constante mudança" (SANCHES, 2012, p. 12). Não obstante o dinamismo inerente ao Direito, o período pós-moderno, marcado pelo amplo acesso a meios de comunicação, percebe-se que, de forma negativa, as massas são facilmente influenciadas e influenciadoras do poder legislativo e, as consequências dessa dinâmica são leis ad hoc ou emergências, destinadas apenas a um contentamento momentâneo. Vivenciamos uma modernidade líquida, entendida como "[...] liquefação dos padrões de dependência e interação. [...], mas como todos os fluidos, eles não mantem a forma por muito tempo" (BAUMAN, 2014, p.15), com isso ocasionando sérios impactos nas leis penais.

A presente pesquisa, com a análise de alguns projetos legislativos que estão tramitando no Congresso Nacional, buscou demonstrar as consequências da modernidade líquida, que a todo instante está destruindo os sólidos modernos, entendidos esses como tipos penais já existentes, para reconstruí-los. O Estado de Direito, que reconhece a existência de certos limites legais, traçando limites à atuação do próprio Estado (REALE, 2002, p, 196), não pode sucumbir a leis emergência, que não são amplamente debatidas, sendo que o debate é essencial para a legitimidade da lei.

O objetivo em analisar a dinâmica da modernidade líquida e suas consequências que são leis emergências é provocar um necessário debate no âmbito acadêmico, haja vista que cabe aos juristas a defesa do ordenamento jurídico e, também, a conscientização da sociedade de que os direitos e garantias fundamentais não devem ser deixados de lado quando surgem sentimento de vingança, frente à ocorrência de determinados crimes, que nada se assemelha a finalidade jurídica que é a justiça. O estudo das leis ad hoc, criadas em situações de efervescência, tem a finalidade de demonstrar que nos momentos de fragilidade, propostas contrárias ao Estado de Direito são aceitas sem debates jurídicos adequado.

\section{METODOLOGIA}

O artigo foi desenvolvido com pesquisas bibliográficas, realizando leituras de leis e projetos de lei, doutrinas e artigos eletrônicos. O método utilizado foi dedutivo, sendo que as informações (estudos) coletados foram analisados e confrontados, considerando-se fatores históricos e filosóficos para se chegar a um resultado crítico e reflexivo sobre o problema de se utilizar a legislação penal como um meio paliativo e ilusório de se frear a violência e a criminalidade, transgredindo princípios do Direito Penal e sua função no Estado de Direito.

\section{RESULTADO}

O estudo das leis ad hoc, criadas em situações de efervescência, acaba por demonstrar que nos momentos de fragilidade, propostas contrárias ao Estado de Direito são aceitas sem debates jurídicos. Cabe, dessa forma, aos juristas combater com ideias, estudos e trabalhos, esses projetos legislativos. Para isso, deve-se deixar de lado a passionalidade e, armando-se com a razão jurídica e a ética e, lembrando o significado do Direito Penal; dos princípios que o norteiam; da função da pena e que também, o criminoso ainda é um cidadão portador de direitos e, por fim, lembrar que por mais repugnantes que alguns fatos possam parecer, não se pode privar o criminoso de alguns direitos, garantidos pelo próprio Estado de Direito, a todos 
os cidadãos. A análise da finalidade da pena, no Estado de Direito, traz a inevitável conclusão de que o seu desiderato não é a vingança.

\section{DISCUSSÃO:}

\section{A MODERNIDADE LIQUIDA E O DIREITO}

$\mathrm{Na}$ teoria da modernidade líquida, destaca-se o motivo da metáfora do líquido, para descrever esse momento contemporâneo que vivemos (transição da modernidade para a pósmodernidade), conforme aponta Zygmunt Bauman que (2000, p. 8) "o que todas essas características dos fluidos mostram, em linguagem simples, é que os líquidos diferentemente dos sólidos não mantem sua forma com facilidade. Os fluidos, por assim dizer, não fixam o espaço nem prendem o tempo". Ora, a liquidez é fundamental para compreender esse moderno fenômeno, marcado pela instabilidade social.

As relações na modernidade líquida são precárias, feitas para se extinguirem e, se o Direito acompanhar essa dinâmica e velocidade, o resulta será as leis emergências, feitas para os movimentos da sociedade. Não se descuida que o Direito, sobretudo o Direito Penal sofre influência dos novos paradigmas sociais que surgem, fruto da necessária reflexão sobre a finalidade do Direito. Nas ciências jurídicas, o surgimento das prisões, a declaração universal de Direitos Humanos, os regimes Democráticos são frutos da modernidade da reflexão sobre a temática Direito - Justiça e dignidade humana e, por ora, são sólidos pós-modernos.

A modernidade líquida apresenta o movimento de transição da pré-modernidade para a modernidade, e de forma contemporânea a modernidade para a pós-modernidade.

“A expressão 'pós-modernidade' batiza um contexto sócio histórico particular, que se funda na base de reflexões críticas acerca do esgotamento dos paradigmas instituídos e construídos pela modernidade ocidental" (BITTAR,2008, p.132). O objeto de análise passa a ser os "paradigmas" frutos da modernidade, os "novos sólidos" que ocuparam o espaço deixado pelos "sólidos enferrujados pré-modernos".

Na presente linha de entendimento, lembra-se que o Direito Penal é um instrumento de controle social por meio do qual o Estado soberano aplica penalidade aos indivíduos que cometem condutas valoradas como crime e, a questão é sopesar em que medida as transformações sociais podem afetar, negativamente, o Direito Penal. A relevância do presente pensamento decorre do fato de que as mudanças sociais afetam o mundo e o campo jurídico, sobretudo, fazendo a sociedade repensar a forma de punir os infratores, pois a forma antiga (até então um sólido enferrujado) não apresentava mais o resultado esperado. A modernidade produziu um novo "sólido" durável e confiável, para essa sociedade. As primeiras instituições destinadas a correção de delinquentes surgiram em 1697 na Inglaterra, com o nome de workhouse (casa de trabalho) (BITENCOURT, p 585.).

Os "sólidos" das penas de morte e infames, foi "derretido" e substituído pelas prisões, que são destinadas a privar o indivíduo de sua liberdade e reintegrá-lo a sociedade.

Direito é resultado das relações sociais e, contemporaneamente, os meios de comunicação da pós-modernidade, como a internet, facilitam a propagação de ideias, produtos e objetos destinados ao consumo, tanto físico quanto intelectual, ocasionando mudanças no cotidiano social. A facilidade de propagação de pensamentos acarreta uma mudança rápida dos valores sociais, ocasionando pressões efêmeras no Poder Legislativo. Isso traz o surgimento de leis penais emergenciais que podem afetar a fragmentariedade do Direito Penal.

\section{DERRETIMENTOS CONSTANTES NA MODERNIDADE LÍQUIDA}


Em um mundo com internet, WhatsApp, Facebook e inúmeras redes sociais, o indivíduo é exposto diariamente a inúmeros pensamentos e ideologias, além do turbilhão de notícias, verdadeiras e falsas

Na modernidade líquida, as informações também possuem a marca da efemeridade, liquidez e volatilidade. Em curtos espaços de tempo, os focos de debate da opinião pública se alteram de forma rápida, os fatos importam menos do que as emoções e as condutas da opinião pública se alteram constantemente, desse modo como o legislador deve se comporta frente a esse fenômeno. Bittar (2008, p.135) nos apresenta a seguinte reflexão:

Se o Direito pressupõe certa estabilização de valores majoritários ou consensuais para que a norma exerça seu poder de escolha de conteúdos normativos, a pergunta, num momento transitivo, acaba sendo; quais os consensos possíveis num mundo de transformação?

\section{LEIS PENAIS EMERGENCIAIS E O ESTADO DE DIREITO}

O poder legislativo pressionado pela sociedade oferece respostas imediata aos cidadãos, nesse sentido é possível destacar a proposta legislativa número 5452/2016, de autoria da Senadora Vanessa Grazziotin. Dentre as muitas alterações apresentadas por esse projeto legislativo a tipificação da conduta conhecida como revenge porn, onde há divulgação sem consentimento da vítima de cena de sexo, nudez ou pornografia, apresenta a utilização do direito penal máximo.

Uma proposta legislativa com esse teor é fruto dos avanços tecnológicos e da interação do homem com tais ferramentas, uma característica da pós-modernidade é a velocidade de troca de informações, dessa forma é evidente que surjam tais condutas reprováveis como reven porn, todavia, sanções pecuniárias da esfera civil (danos morais) e a destruição do conteúdo são medidas adequadas. É importante lembrar que o Direito Penal deve ser aplicado de forma subsidiaria como destaca Rogério Greco (2016, p 77):

[..]O princípio da intervenção mínima deixa entrever a necessidade de o Direito Penal ser aplicado de forma subsidiária, tendo em vista a drasticidade de sua resposta, permitindo assim, ancorado no princípio da dignidade da pessoa humana, que outros ramos do ordenamento jurídico, com primazia, procurem fazer a proteção dos bens jurídicos, somente sendo necessária a interferência do Direito Penal quando esses outros ramos demonstrarem que são ineficazes ou insuficiente a sua proteção.

O Estado deve se adaptar aos avanços e mudanças da sociedade, todavia, não cabe ao Direito Penal, tutelar todas as ofensas, impondo sanções drásticas, como no citado projeto de lei, o Estado deveria buscar outros meios de coibir essa conduta que fere a dignidade sexual, pode-se buscar condenações na esfera Civil e a privação de liberdade deve figurar como a última alternativa a repressão da conduta.

O projeto da Senadora Vanessa Grazziotin foi protocolado no dia 16-09-2015 tramitando de forma ordinária no Senado Federal, contudo no dia 31-05-2016 foi apresentado o requerimento de número 384 solicitando urgência na tramitação, no dia 01-06-2016 foi encaminhado a Mesa Diretora da Câmara dos Deputados, uma resposta rápida a sociedade que discutia durante esse período um caso de estupro coletivo que ocorreu no dia 21-05-2016, onde uma jovem de 16 anos foi filmada desacordada e sendo violentada por 33 homens.

A influência da sociedade fez que o projeto tramitasse em regime de urgência e, também que um delegado que acompanhava o caso fosse destituído, fomentando o debate sobre a cultura do estupro em toda sociedade. A pós-modernidade encurta distâncias e dissemina informações, influência na criação e aplicação da lei, como destacamos acima.

\section{CONCLUSÃO: DIREITO E A MODERNIDADE LÍQUIDA}


Quanto a formação da norma jurídica e seus elementos essências, Miguel Reale (2012, p. 59) apresenta a estrutura tridimensional do direito:

Onde quer que haja um fenômeno jurídico, há, sempre e necessariamente, um fato subjacente (fato econômico, geográfico, demográfico, de ordem técnica etc.); um valor, que confere determinada significação a esse fato, inclinando ou determinando a ação dos homens no sentido de atingir ou preservar certa finalidade ou objetivo; e, finalmente, uma regra ou norma, que representa a relação ou medida que integra um daqueles elementos ao outro, o fato ao valor.

Na teoria tridimensional do direito (MIGUEL REALE, 1968), um fato jurídico é um valor são ligados pela norma, todavia, na modernidade líquida os valores são apresentados de forma efêmera, instável e de fácil volatilidade, desse modo, os fatos possuem maior peso na construção da norma, contribuindo dessa forma para a proposição de mudanças legislativas em momentos de efervescência social.

A interação do cidadão com o Estado que está sofrendo a liquefação, leis são sólidos jurídicos que estão passando ao estado de fluidos e são moldados conforme a necessidade apresentada pela sociedade, pois como Bauman destaca (2014, p.15) "Dar-Ihes forma é mais fácil que mantê-los nela" por isso, as mudanças constates e rápidas na legislação, o projeto de lei da Senadora Vanessa, tramitava em rito ordinário no Senado Federal, mas a ocorrência de um fato de grande repercussão fez com que passasse a regime de urgência, pois na modernidade líquida, os valores são alterados conforme a repercussão dos fatos.

Outra caraterística da modernidade líquida é o encurtamento de distancias, um fato como um crime bárbaro, pode ser conhecido por toda a sociedade em poucas horas. Esses fatores contribuem para uma sociedade que produz leis penais emergências, que atentam contra o Estado de Direito, pois utilizam o instrumento de coerção social, direito penal, como meio de legitimar a vinganças e não aplicar a justiça.

O Estado de Direito, que reconhece a existência dos limites públicos subjetivos e traça limites a atuação do próprio Estado (REALE. 2002, p, 196), não pode sucumbir a leis emergência, que são propostas e criadas em meio ao clamor social.

\section{REFERÊNCIAS}

BAUMAN, Zygmunt Ensaios Sobre O Conceito De Cultura São Paulo: Editora Zahar, 2001.

BAUMAN, Zygmunt. Modernidade líquida. São Paulo: Editora Zahar, 2001.

BITTAR, Eduardo Carlos Bianca, O Direito na Pós-Modernidade, revista sequência, nำ57 dezembro de 2008.

BRASIL, Constituição (1988). Constituição: República Federativa do Brasil. Brasília, DF: Senado Federal, 1988.

BRASIL. Câmara dos Deputados. Projeto de lei no 5.452, 16 de setembro de 2015, Autora: Vanessa Grazziotin, Câmara dos Deputados, Brasília, DF 01 jun. 2016. Disponível em: < http://www.camara.gov.br/proposicoesWeb/prop_mostrarintegra?codteor=1463123\&filenam e=Tramitacao-PL+5452/2016>. Acesso em: 07 de dez. 2017.

BITENCOURT, Cesar Roberto, Tratado de Direito Penal, São Paulo, Editora Saraiva, edição 22, 2016. 
GRECO, Rogerio, Direito Penal do Equilíbrio, Niterói, Rio de Janeiro, Editora Impetus, 9 Edição, 2016.

REALE, Miguel, Introdução à Filosofia, São Paulo, Editora Saraiva, 2002.

SANCHES, Cunha, Introdução ao Estudo do Direito, São Paulo, Editora Saraiva, Coleção Saberes Direito 1, 2012. 